\title{
THE CYCLE YEAR 1905 AND THE COMING SEASON.
}

\author{
By D. E. Hutchins, F.R.Met.Soc.
}

(Read November 29, 1905.)

The year 1905 is an important one to those who are interested in long-period weather forecasts. The year 1905 is the calculated maximum of sunspots, and, so far as one can judge by the sun's present appearance, it is likely to be the year of actual maximum sunspots. The year 1905 is a maximum rainfall year according to another of my Cape cycle years, namely, the 12.5 -year cycle, which, in compliment to Dr. Meldrum (one of the first investigators in this field of inquiry), I have named Meldrum's cycle. And Broekner's 35-year cycle comes also into operation, as I shall explain later. We have thus as regards the year 1905 and the coming season three cycles favourable to good seasons. I propose now to glance briefly at each of these cycles, and then to consider what may be their effect on the coming season.

\section{Sunspot or Solar Cycle of 11.11 Years.}

The solar cycle has a mean period of $11 \cdot 11$ years. Sunspots have been observed to have a period which is sometimes so much more than 11 years, and sometimes so much less, that occasionally we have a maximum getting into the place of a minimum, or vice versâ. This has occurred twice since sunspots have been under observation, but other solar phenomena, such as faculæ and terrestrial phenomena, which are directly dependent upon the solar cycle, show less variation than the sunspots as observed. For the purposes of my forecasts, prepared in 1888, I have adhered to the mean period of 11.11 years, and the rains which are reasonably referable to the solar period, it will be seen from the cyclical diagram on the wall, have not varied more than a year from the 11.11 period. Thus, in 1850 the sunspot rains were punctual at the sunspot maximum; in 1861 these rains came a year late; in 1872 they were punctual; in 1883 they were punctual; in 1895 they came a year late. The 
next sunspot or, to speak more correctly, solar period brings us to 1905-the present year-and this seems likely to be the maximum year of observed sunspots. For some months the sun has been rarely free from spots, several visible without any magnifying power. Yesterday an ordinary field-glass showed four spots ranged in a long line in the sun's southern hemisphere.

In connection with sunspot rains there is a feature which I have referred to in some of the cyclical diagrams as "Lag" rains. The cyclical diagrams on the wall for Grahamstown and Durban show "Lag" rains in 1874 at Durban, and at Grahamstown in 1874 and 1886. On some of the other long-period rainfall records these "Lag" rains are more in evidence. On the Maritzburg-Gardens-cliff cyclical diagram they are in evidence in 1864 (one year late), in 1874, and (weakly) in 1896. They will be found discussed in my "Cycles of Drought and Good Seasons," published in 1888. They are not noticeable in recent years, and as the record extends it may be found necessary to abandon them as unproven. Some of them may be connected with sunspots as observed. But I am inclined to attach little importance to observed sunspots. I have in all my work confined myself to the solar cycle of $11 \cdot 11$ years, and that this is the correct view to take appears to be borne out in the diagrams before you. In 1870 occurred the strongest maximum of sunspots observed in that century. During that year and the preceding year and the following year there was drought in South Africa. The solar maximum, according to the $11 \cdot 11$ period, fell in 1872 , and with it came good rains east and west in South Africa. As Sir Norman Lockyer observes (Nature, July 15, 1905), sunspots are only one and a very partial expression of solar energy.

\section{Meldrum's Cycle of 12 and 13 Years alternating.}

In my work, "Cycles of Drought and Good Seasons in South Africa," referred to above, this will be found described at page 104 as "the Mitigation Drought of the sunspot minimum," since they first appeared in the guise of a break in droughts which were connected with the sunspot minimum. Further research led me to modify this view, and to regard these rains as of equal importance with the other two cycles of Cape rainfall. Sir Norman Lockyer and Dr. Lockyer, of the Solar Physics Observatory, Kensington, have shown that good rains in India occur at periods of maximum and minimum sunspots; and Sir John Eliot, and I subsequently (Nature, February 9, 1905), have shown that there has during the last 10 years been a connection between good rains in India and 
good rains in South Africa, so that the mitigation rains in my early work resolve themselves into light rains at the sun spotminimum and heavy cycle rains at intervals of 12 and 13 years alternating. This cycle of 12 and 13 years alternating (or $12 \frac{1}{2}$ years as a mean period) I termed Meldrum's cycle, at the conclusion of my work in 1888, as a compliment to Meldrum, the eminent Mauritius astronomer, who was the first to connect in an unmistakable manner solar activity with terrestrial meteorological phenomena. As early as 1876 Meldrum's view was accepted that there was an unmistakable connection between the frequency of sunspots and hurricanes in the Indian Ocean. If Meldrum's cycle continues as it promises, it will be pleasant in this way to perpetuate Meldrum's name. In 1892 the 12.5-year cycle brought almost the heaviest rains ever experienced to the Cape Peninsula and the south-west. We are concerned with it to-night, since it is again before us in 1905 .

\section{Brïckner's Cycle of 35 Years.}

Brückner, as you are aware, has made extensive researches which tend to show that a large class of terrestrial meteorological phenomena recur at a period of about 35 years. Brückner's 35-year cycle has been confirmed and extended by the researches of J. Hann and by the results of Richter's study on the variations in the Swiss glaciers. Brückner's discovery arose out of a study of the varying levels of the Caspian Sea, which, being a closed inland sea, furnishes an index of the variations of rainfall over the wide area draining into the Caspian Sea-an area extending north even above Moscow. (Russel has followed a similar line of inquiry with regard to Lake George, in New South Wales, and by and by data from the African lakes will be precious.)

Brückner published some of his most important results in 1890 . This year these results have found their way into the daily press with reference to the fierce criticism that has been raised over ordinary short-period weather forecasting and long-period forecasting. It has been claimed by the admirers of Brückner in the public press that his researches would enable us to predict the characters of seasons in a practical way, which would be an immense advantage to the world at large. This, I need not say, is a result which has not yet been arrived at. Brückner's researches, widespreading and important though they are, lack that element of precision which is seen in the Cape weather cycles. I am mentioning Brückner's cycle this evening because, although his maximum rain period has been fixed about 1878,1879 , or 1880 , and thus should 
not recur till somewhere about 1914, yet it is part of the Lockyer cyclical work to connect Brückner's cycle with a major cycle of sunspots. Now, 1870 was the big sunspot maximum of the century, and 1870 plus 35 will bring us to 1905, our present year. To repeat, then, although 1905 is not Brückner's year of maximum rainfall, the Lockyer discovery makes it a particularly important year of maximum sunspots.

South African rainfall records are too short to afford much scope for studying the influence of Brückner's cycle on South African rainfall. The Royal Observatory has rainfall records for 64 years, and Maritzburg-Gardenscliff, in Natal, for 51 years. These show no tendency for rainfall to recur in 35 years; but two very dry years at the Royal Observatory are separated by 35 years, and two droughts in Natal recur at 35 years. It is too soon yet to say whether this correspondence is accidental.

\section{The "Storm" Cycle of 9 and 10 Years alternating.}

Two years ahead lies the most powerful of the three Cape weather cycles-the so-called “Storm cycle." This I propose to discuss next year. It is for practical purposes the same as Russel's 19-year Australian weather cycle. This cycle has also cropped up in other countries. It is noteworthy that 19 years is the period of revolution of the moon's nodes.

\section{Cyclical Diagrams.}

With this explanation of the three Cape weather cycles I will now proceed to call your attention to the cyclical diagrams on the wall. I have selected these out of a much larger number in my possession to which, it will be understood, I refer in the course of the following remarks. The diagrams selected, namely, Royal Observatory, Cape Town: Grahamstown : and Durban : have been chosen on account of the length and reliability of their records. The first point that will strike you on looking at these cyclical diagrams is the wonderful regularity with which South African rains fit into these three weather cycles. I know of no other country in the world where the rainfall shows the same regularity.

For the light, though precious, rains of the interior districts less dependence can be placed on cyclical regularity. To a large extent the cyclical rains are masked by irregular and by local rains. But I have seen no South African rainfall where the indications of cyclical influence could not be traced.

Brückner's world-wide researches show a reversal phase for inland 


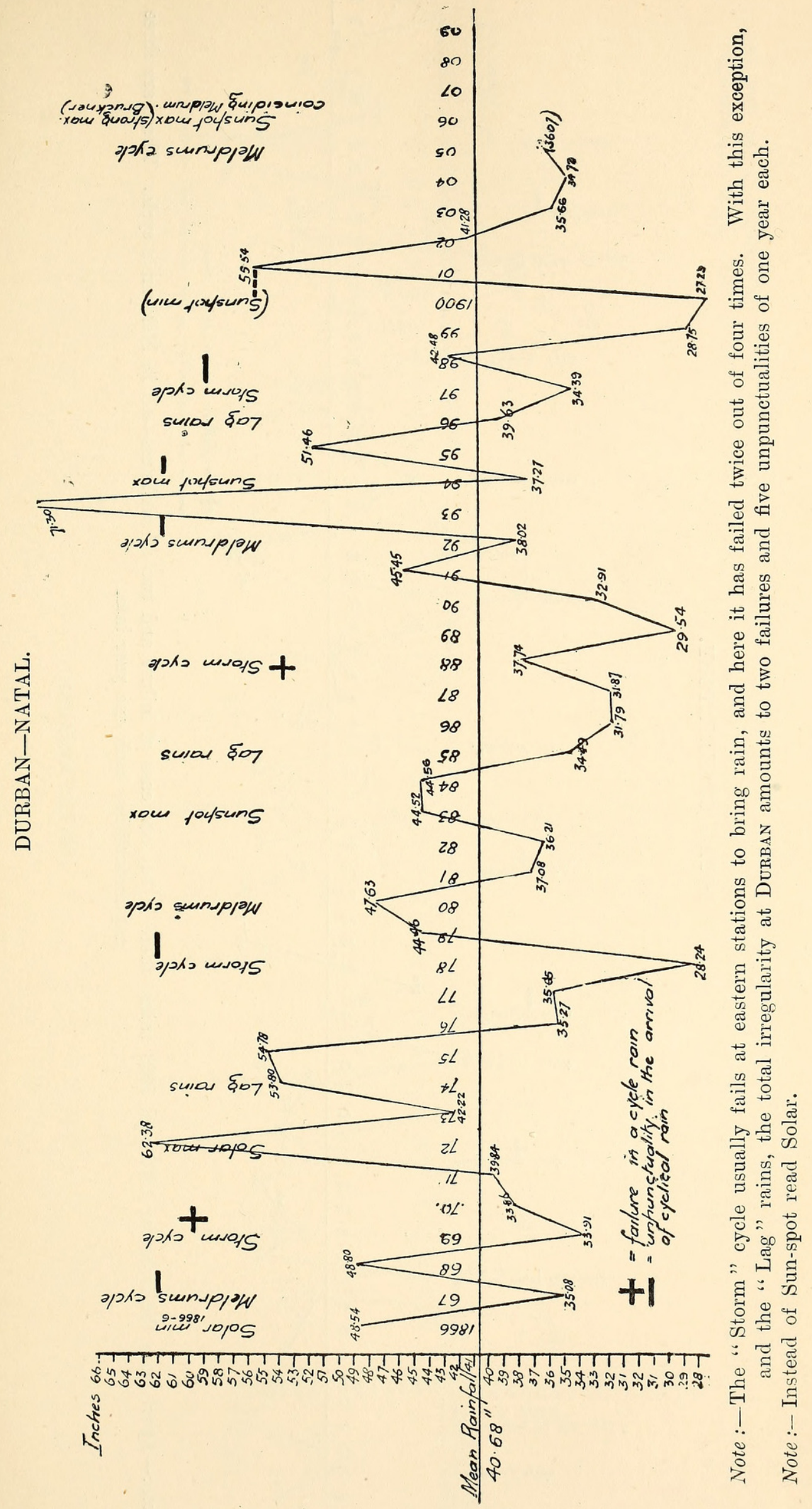




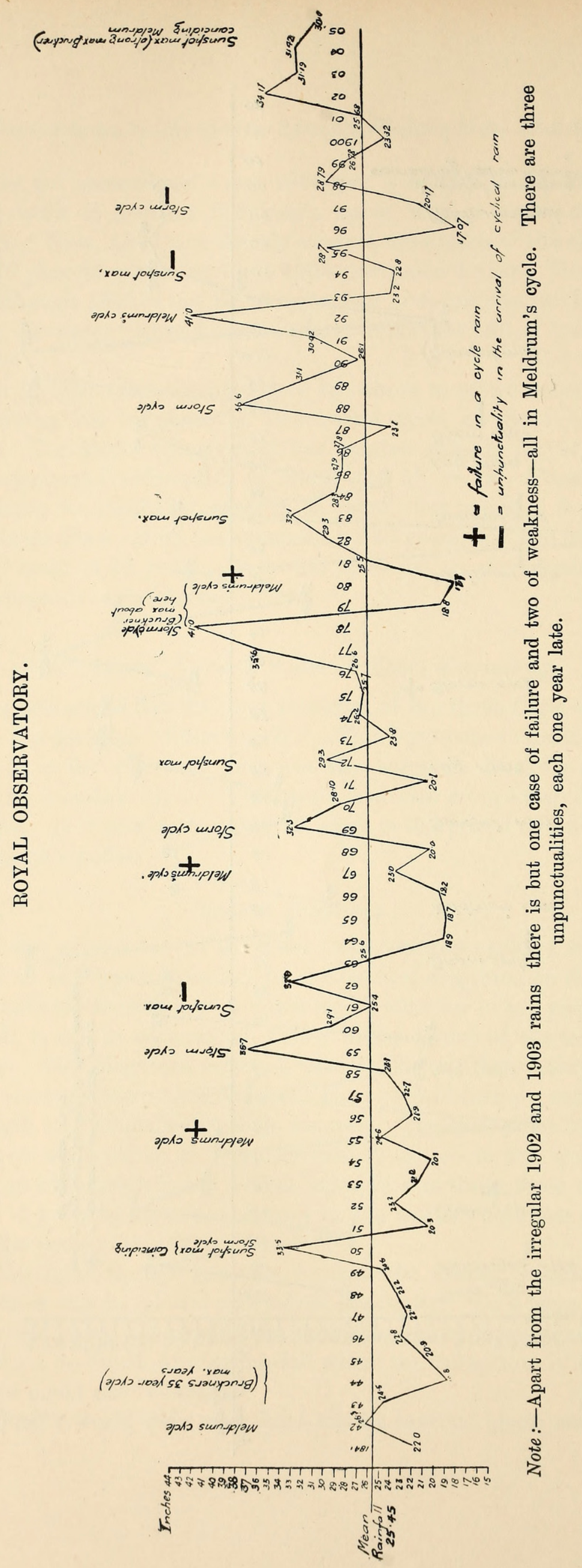




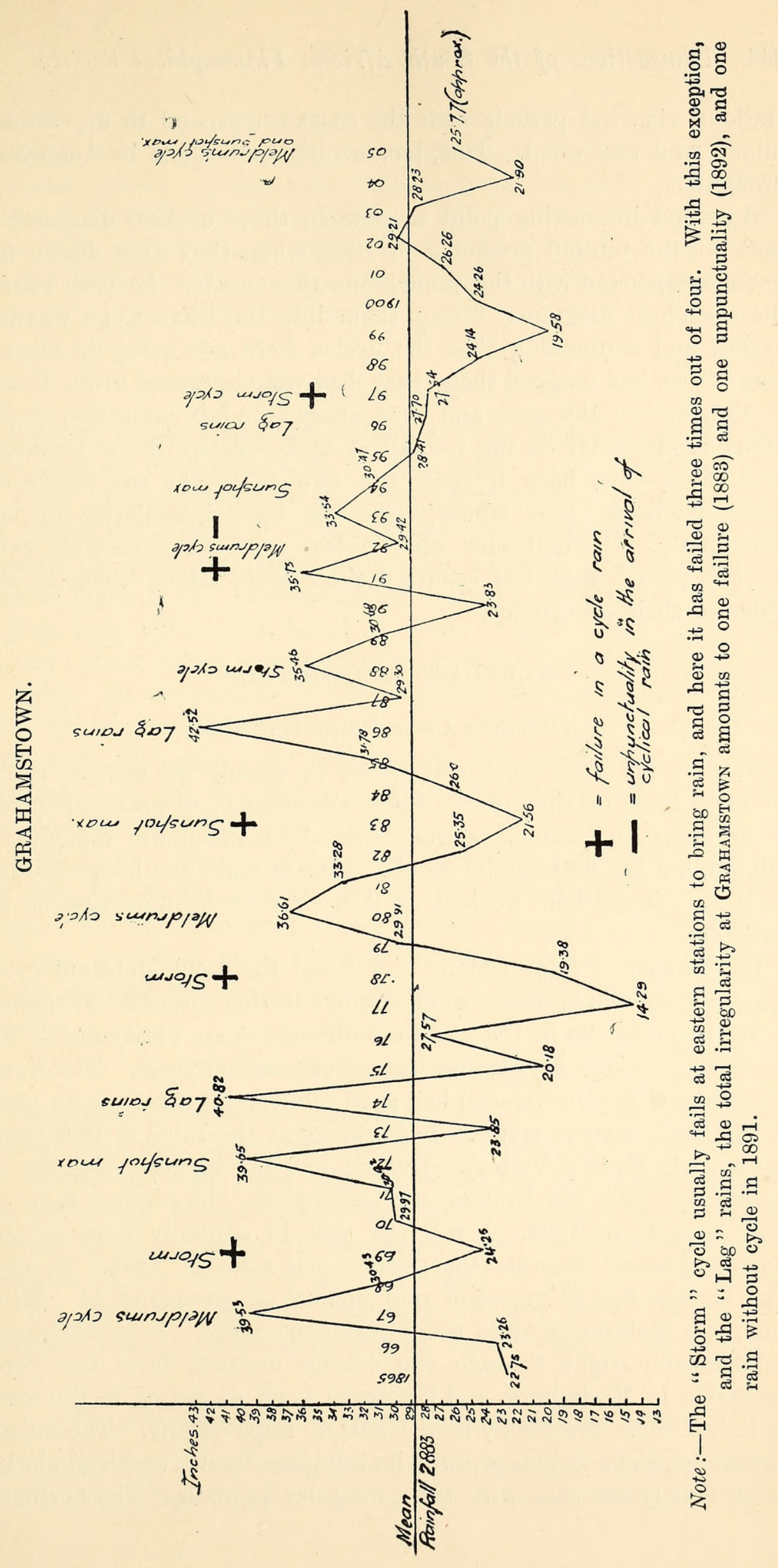


stations, viz., wet periods near the coast correspond to dry periods inland, and vice versâ. This, too, is often noticeable in Australian droughts.

A second interesting point to note in these cyclical diagrams is how far the rainfall predicted in 1888, when they were drawn up, has corresponded with the predictions then made. In 1888 I drew these cyclical diagrams, fitting them into the three Cape weather cycles, and contending that the cycles were not going to change because we had mapped them, that they would proceed in the future as they had in the past, and thus afford us a fair indication of the probable character of the rainfall of each season. How far these predictions have been fulfilled you now see. The red marks on these diagrams show where there has been irregularity or unpunctuality. I shall now offer a few remarks regarding each rainfall period that has occurred since 1888, taking them in the order of their occurrence.

\section{FORECAST AND RESULT.}

\section{Meldrum's Cycle Rainfall in 1892.}

This in my 1888 work was noted as mainly an eastern cycle. The first three maxima on the Royal Observatory diagram all agreed in bringing only a small rainfall; the fourth maximum brought no rainfall, but the first maximum after 1888 brought the heavy rainfall of 1892. Here, then, we had, as it were, a cycle improving on its forecast!

In the east of Cape Colony and Natal the 1892 Meldrum cycle rains ran over three years, some stations having the heaviest rainfall in 1891, and others in 1893. These differences are partly due to the records being kept in calendar instead of seasonal years. The Natal inland districts (Maritzburg) had good rains on all three years; most of the Cape eastern stations had a break of the rains in 1892 (note particularly Evelyn Valley). Durban had the highest rains on its records in 1893, and Umtata and Queenstown the highest rains in their records in 1891. I will ask you to carefully note on the Durban cyclical diagram the phenomenal rains of 1893 . In that year Durban had 71 inches of rain, against an average of 41 . This, then, was Meldrum's cycle at its last appearance. It showed itself unmistakably right through the coastal districts from the Cape Peninsula to Maritzburg, and it showed itself as strong in the west as it had done previously in the east of Cape Colony. The inland districts of Cape Colony showed its influence faintly and irregularly, as is usually the case with their irregular rainfalls. The northern 
colonies show the same remarkably heavy rainfalls, but a year, or perhaps two, sooner (the records from these stations are not in calendar years). There have been nothing like such rains since either at Johannesburg or Bulawayo. We know now that as regards 1905 this cycle has not come in a pronounced form a year sooner at the northern stations; but we must not forget the interference of the two cycles this year-1905.

\section{The Solar Cycle Rains of 1894.}

Looking at the Royal Observatory cyclical diagram, you will see that the solar maximum rains of 1894 came weak and a year late in 1895. The weakness on the Royal Observatory diagram is local. At Ceres, the other end of the axis of heavy western rainfall, the rainfall for 1895 was $57 \frac{1}{2}$, against an average of 39 inches. At eastern stations the solar maximum rains of 1894 failed or came a year late. The rains failed at many eastern stations in Cape Colony ; there were pronounced rains in Natal, but a year late, viz., in 1895. At all stations in Cape Colony where these solar rains were felt they came a year late. At northern stations, Johannesburg and Bulawayo, the solar rains were well developed and punctual, and, like the Meldrum cycle rains mentioned above, they came $a$ year before the Cape rains.

"Lag" solar rains can be seen for certain nowhere. This is perhaps due to the interference of the more powerful "Storm" cycle. As we have seen, these "Lag" rains have on certain previous occasions been strongly marked, so that their failure, owing perhaps to the interference of the Storm cycle in 1897, is notable.

\section{The Storm Cycle Rains of 1897.}

There were some violent storms in 1897. (In July of that year a railway train was blown over bodily as it stood in a siding between Woodstock and Salt River, near Cape Town.) But the rainfall was late and weak. It was weak at most stations, and a year late at all stations in Cape Colony and the Natal coast. As on every previous occasion for the last 65 years, it brought no rain to Maritzburg. At the northern stations, Johannesburg and Bulawayo, it was punctual, coming again about a year sooner than in the south.

\section{The Irregular Rains of 1902, 1903, in the South-west.}

I am not here this evening to undertake special pleading on behalf of the three Cape weather cycles, and I freely admit that these 
rains in the south-west came as a surprise to me. If you run the eye over the whole of the rainfall registered at the Royal Observatory back as far as the year 1841, it will be seen at a glance that there is nothing nearly so abnormal as the rains of 1902 and 1903 . I predicted rains about then, connected with the sunspot minimum, but I did not think these rains would extend to the south-west. In the event they went right through South Africa, from Cape Town to Salisbury in Rhodesia; and, like all the other cycle rains, they began in the north first. In the Cape Peninsula and Malmesbury they began in 1902 and lasted till 1904; but this duration was local. At Ceres, the inland side of the axis of heavy rainfall in the south-west, they had less than three-fourths the average rainfall in 1903. Going eastward, we see irregular distribution at once in the incidence of this abnormal rain. Grahamstown and King William's Town had practically none of it. At the two neighbouring high-level stations Evelyn Valley had tremendous rains in 1903, while Katberg had none. Again Aliwal got simply a drought mitigation in 1902 ; Aliwal and Queenstown moderate rains in 1901.

A possible explanation occurs to me with regard to the abnormal 1902 rains. They may be due to the delayed and irregular sunspot minimum. The sunspot minimum was due in 1900, and at Salisbury, the most northern station, heavy rains set in in 1899, and continued until 1901, while at Bulawayo the rains were slightly above the average in 1901 and 1902. Coming further south to Johannesburg, we find well-developed rains in 1901 and 1902 ; and further south to Natal, we find that Durban had heavy rains in 1901, while Maritzburg shared the 1902 rains of the west of Cape Colony. We thus see a chain of irregular rains extending from north southwards, and it seems possible to regard these as in some way connected with the irregular sunspot minimum of those years.

In 1901 came the extraordinary summer rains in the south-west of Cape Colony ; in January of that year 5 inches of rain were registered at the Royal Observatory. And these abnormal rains extended to New Zealand, but not to Australia.

Nevertheless except for the small south-west area of winter rains, the irregular rains of 1901-1902 were correctly forecasted. Page 109 of "Cycles of Drought and Good Seasons," published in 1888, reads, “1889, 1900, 1901, 1902, 1903, all years of drought, with an irregular mitigation of one or two years, good or average rainfall, occurring most probably about 1901."

In the Annual Report of the Meteorological Commission for 1902 is one of those interesting graphical diagrams which the Secretary to the Meteorological Commission contrives to give us, from time to 
time, out of his slender resources. In this diagram is shown the monthly incidence of the 1902 rainfall. This diagram shows us exactly during what months and over what areas the irregular 1902 rains fell. In the Cape Peninsula they culminated in June and September. The heavy June rain of Cape Town was absent in the south-west generally, but the September rains ran through the whole of the southern and western coast districts. In the summer rainfall areas of South Africa the rains came during spring and autumn, except in Kaffraria, where there was rain in June. But the most instructive part of the diagram is the "abnormality" one. This shows that the abnormal rains throughout South Africa occurred almost entirely in June and September. In July there was a drop to normal rainfall. There was abnormal drought during spring and autumn, and slight drought during July.

The same diagram published with the Meteorological Commission Report for 1903 shows that the excessive rain occurred in June in the south-west and in November on the southern coast. Though the rainfall amounted to 94 inches on Table Mountain (St. Michael's), the general character of the year in Cape Colony was " an exceptionally severe drought lasting throughout the year," the year's mean for all Cape stations being 19 per cent. below the normal (Report of Meteorological Commission for 1903).

The real significance of these 1902 and 1903 irregular rains will be seen when it is considered that the effect of them and of the unusually heavy last Meldrum cycle rains (1892) has been to raise the mean rainfall of the Royal Observatory by nearly $\frac{1}{2}$ inch. Up to 1888 the mean rainfall at the Royal Observatory was 25.43 inches. It is now 25.9 inches.

\section{CONCLUSIONS.}

In view of the more ample material that has accumulated since 1888 the following conclusions seem justified:-

1. The three main weather cycles are of general application throughout South Africa. I had considered in 1888 that the Storm cycle brought practically no rain to the eastern stations, and Meldrum's cycle little or no rain to western stations. The experience of the last 17 years shows that both may extend east and west beyond their area of greatest influence.

2. Observations from the northern stations are as yet too short to draw safe conclusions, but they seem to indicate that the pulse of heavier rainfall occurs a season earlier at northern stations (Transvaal and Rhodesia). 
3. There are obscure indications of a tendency to rain at the sunspot minimum, and possibly the irregular rain of 1902 may be accounted for as a sunspot minimum rain. It so happens that the normal sunspot minimum periods $(11-22-33-44-55 \cdot 5-67-78$ -89-100 in each century) have since the year 1841 so frequently coincided with other cycles that the exact influence of the sunspot minimum is difficult to trace. In the long chain of the Royal Observatory rainfall figures the sunspot minimum has had no practical influence till we get to the doubtful case of the 1902 rains. At other stations sunspot minimum rains are more clearly traceable. Note the rains of 1866 at Durban, of 1900 at Bulawayo, Salisbury, and Johannesburg. Further observations are necessary before it can be stated what is the exact influence of the sunspot minimum on South African weather.

4. Up to the present the direct influence of Brückner's 35-year cycle is inappreciable in South African weather.

\section{FORECAST FOR THE ENSUING YEAR.}

As on previous occasions, this forecast is based (1) on the cyclical indications, and (2) on such information as is obtainable of the weather prevailing in neighbouring areas. In the light of what has been said above the present cyclical position will, I hope, be clearly understood. 1905 is a double-cycle year; that is to say, the solar cycle and Meldrum's cycle coincide. In my forecasts, published in 1888, the following appears against the year 1905: "Most probably general good rains. There is no precedent in meteorological records for these two cycles coinciding." For 1906 appears the entry : "Probably good rains with drought at a few stations." The rains so far in 1905 have been heavy at intervals and marked by violent storms -witness the storm at Durban and those in the Cape Peninsula at about the time when a large portion of the town of Malmesbury was destroyed by a storrn; but the total of the 1905 rains has been moderate in the Cape Peninsula and also in the north. In the Cape Peninsula we may regard the 1905 rains as practically finished, and assume a total of 29.5 inches. This is less than 4 inches above the average. From the north, where the summer rains have already decidedly set in, I have the following data :-

From Zomba it is reported that good rains have set in for the last two months, and with the exception of strong, fitful easterly winds, the season is normal. 
In Rhodesia the rains during September and October have been less than usual, with consequently higher temperatures. Wind velocity normal.

So far this season in the Transvaal has been drier at most stations than last year, but there has been more rain at Pretoria, though less at Johannesburg. At Pilgrim's Rest and other eastern stations there has been so far considerably less rain this spring than last spring.

Lake Chrissie, in one of the wettest parts of the eastern Transvaal, affords a practical illustration of the effects of the recent droughts. The case is mentioned in a report just issued by the Transvaal Meteorological Department. “There is a legend among the Boers of the district that if ever Lake Chrissie dried up the Dutch people would lose their independence. During the latter part of the war the lake was perfectly dry for the first time during the memory of man." I visited Lake Chrissie towards the end of the winter of 1903 . It was then a noble sheet of water, but, I was informed, shallower than in the old times. In 1904 Lake Chrissie dried up, and it has been dry again this last winter of 1905 .

\section{Rains in the Nile Basin.}

The Director-General of the Survey Department, Cairo, writing under date, November 8, 1905, states that this year's Nile flood has been markedly below the average. The rains both in Abyssinia and in the equatorial Nile regions were weak and late. "At the end of the rainy season there was a general improvement, but still the Abyssinian rains of September and October did not reach the average." There was also some sign of improvement in the rains over the equatorial lakes and Northern Uganda as the rains retired southward. The Director-General summarises this season's rains thus :-

"The rains of 1905 in the Nile basin were very late and weak; little improvement occurred during the season, giving a flood considerably below the average; some late improvement may have taken place in the extreme southern parts of the basin, but this is uncertain."

\section{The Indian Monsoon.}

The Indian Monsoon, except in Burmah, Bengal, Assam, and Bihar, has been a bad one, and the country was only saved from famine by a timely burst of rainfall at the end of September. In the Burmah-Bihar area the average excess was 12.5 per cent. above the normal. Elsewhere-that is to say over the greater portion of 
India-there was an average deficiency of 33 per cent. below the normal. (Dr. G. T. Walker, Meteorological Report to Government of India.)

On the whole, the indications from India are similar to those from Abyssinia and the Nile basin; that is to say, the rains were weak and late in beginning, but showed an improvement at the finish. So that as regards South Africa, the Indian Monsoon does not afford an indication more definite than that of the Nile and Abyssinia. It is worthy of note that the failure of the Indian Monsoon was on the western side; that is to say, that which is nearest to South Africa.

\section{Forecast: Summer Rainfall Area, South Africa generally, except the Southern and South-west Coast of Cape Colony.}

The year 1906 coming between two rainfall periods, there may be short and local droughts, or the rains may run on to the heavy rainfall period which is ahead of us in 1907, and probably 1908. The outlook now is several years of good rainfall ahead.

\section{Forecast: South Coast and South-west.}

Strong south-easters (really southerly and south-westerly winds) may be expected during the summer.

The cyclical indication for next winter's rains is that they will be moderate.

A word of warning may be added in conclusion. Long-period forecasts cannot in the nature of things have anything like the precision attached to the short day-or-two forecasts, which are framed simply on a study of the approaching weather movements. It is perhaps unfortunate that the word "forecast" has been applied at all to long-period weather predictions. In any case, it is advisable to remember that the latter are at best but a calculation of probabilities, and an indication of what may be expected to affect the coming season as a whole.

Thus, farmers may expect general good seasons for the next two or three years, but this is not to say that there will not be drought in certain places; and, as I have mentioned, for the drier inland districts the rains are too irregular for the cyclical forecast to have any practical value. After 1908 there are six years of drought to look forward to, with an irregular mitigation of the drought, most probably about 1911 or 1912 . 


\section{$2 \mathrm{BHL}$ Biodiversity Heritage Library}

Hutchins, D. E. 1905. "THE CYCLE YEAR 1905 AND THE COMING SEASON." Transactions of the South African Philosophical Society 16, 237-250. https://doi.org/10.1080/21560382.1905.9526060.

View This Item Online: https://www.biodiversitylibrary.org/item/113609

DOI: https://doi.org/10.1080/21560382.1905.9526060

Permalink: https://www.biodiversitylibrary.org/partpdf/175331

\section{Holding Institution}

Field Museum of Natural History Library

\section{Sponsored by}

The Field Museum's Africa Council

\section{Copyright \& Reuse}

Copyright Status: NOT_IN_COPYRIGHT

This document was created from content at the Biodiversity Heritage Library, the world's largest open access digital library for biodiversity literature and archives. Visit BHL at https://www.biodiversitylibrary.org. 